\title{
Some Characterizations for a Family of Nonexpansive Mappings and Convergence of a Generated Sequence to Their Common Fixed Point
}

\author{
Yasunori Kimura ${ }^{1}$ and Kazuhide Nakajo ${ }^{2}$ \\ ${ }^{1}$ Department of Mathematical and Computing Sciences, Tokyo Institute of Technology, \\ O-okayama, Meguro-ku, Tokyo 152-8552, Japan \\ ${ }^{2}$ Faculty of Engineering, Tamagawa University, Tamagawa-Gakuen, Machida-shi, Tokyo 194-8610, Japan \\ Correspondence should be addressed to Yasunori Kimura, yasunori@is.titech.ac.jp
}

Received 7 October 2009; Accepted 19 October 2009

Academic Editor: Anthony To Ming Lau

Copyright (C) 2010 Y. Kimura and K. Nakajo. This is an open access article distributed under the Creative Commons Attribution License, which permits unrestricted use, distribution, and reproduction in any medium, provided the original work is properly cited.

Motivated by the method of Xu (2006) and Matsushita and Takahashi (2008), we characterize the set of all common fixed points of a family of nonexpansive mappings by the notion of Mosco convergence and prove strong convergence theorems for nonexpansive mappings and semigroups in a uniformly convex Banach space.

\section{Introduction}

Let $C$ be a nonempty bounded closed convex subset of a Banach space and $T: C \rightarrow C$ a nonexpansive mapping; that is, $T$ satisfies $\|T x-T y\| \leq\|x-y\|$ for any $x, y \in C$, and consider approximating a fixed point of $T$. This problem has been investigated by many researchers and various types of strong convergent algorithm have been established. For implicit algorithms, see Browder [1], Reich [2], Takahashi and Ueda [3], and others. For explicit iterative schemes, see Halpern [4], Wittmann [5], Shioji and Takahashi [6], and others. Nakajo and Takahashi [7] introduced a hybrid type iterative scheme by using the metric projection, and recently Takahashi et al. [8] established a modified type of this projection method, also known as the shrinking projection method.

Let us focus on the following methods generating an approximating sequence to a fixed point of a nonexpansive mapping. Let $C$ be a nonempty bounded closed convex subset of a uniformly convex and smooth Banach space $E$ and let $T$ be a nonexpansive mapping of 
$\mathrm{C}$ into itself. $\mathrm{Xu}[9]$ considered a sequence $\left\{x_{n}\right\}$ generated by

$$
\begin{gathered}
x_{1}=x \in C, \\
C_{n}=\text { clco }\left\{z \in C:\|z-T z\| \leq t_{n}\left\|x_{n}-T x_{n}\right\|\right\}, \\
D_{n}=\left\{z \in C:\left\langle x_{n}-z, J x-J x_{n}\right\rangle \geq 0\right\}, \\
x_{n+1}=\prod_{C_{n} \cap D_{n}} x
\end{gathered}
$$

for each $n \in \mathbb{N}$, where clco $D$ is the closure of the convex hull of $D, \Pi_{C_{n} \cap D_{n}}$ is the generalized projection onto $C_{n} \cap D_{n}$, and $\left\{t_{n}\right\}$ is a sequence in $(0,1)$ with $t_{n} \rightarrow 0$ as $n \rightarrow \infty$. Then, he proved that $\left\{x_{n}\right\}$ converges strongly to $\Pi_{F(T)} x$. Matsushita and Takahashi [10] considered a sequence $\left\{y_{n}\right\}$ generated by

$$
\begin{gathered}
y_{1}=x \in C, \\
C_{n}=\text { clco }\left\{z \in C:\|z-T z\| \leq t_{n}\left\|y_{n}-T y_{n}\right\|\right\}, \\
D_{n}=\left\{z \in C:\left\langle y_{n}-z, J\left(x-y_{n}\right)\right\rangle \geq 0\right\}, \\
y_{n+1}=P_{C_{n} \cap D_{n}} x
\end{gathered}
$$

for each $n \in \mathbb{N}$, where $P_{C_{n} \cap D_{n}}$ is the metric projection onto $C_{n} \cap D_{n}$ and $\left\{t_{n}\right\}$ is a sequence in $(0,1)$ with $t_{n} \rightarrow 0$ as $n \rightarrow \infty$. They proved that $\left\{y_{n}\right\}$ converges strongly to $P_{F(T)} x$.

In this paper, motivated by these results, we characterize the set of all common fixed points of a family of nonexpansive mappings by the notion of Mosco convergence and prove strong convergence theorems for nonexpansive mappings and semigroups in a uniformly convex Banach space.

\section{Preliminaries}

Throughout this paper, we denote by $E$ a real Banach space with norm $\|\cdot\|$. We write $x_{n} \rightarrow x$ to indicate that a sequence $\left\{x_{n}\right\}$ converges weakly to $x$. Similarly, $x_{n} \rightarrow x$ will symbolize strong convergence. Let $G$ be the family of all strictly increasing continuous convex functions $g:[0, \infty) \rightarrow[0, \infty)$ satisfying that $g(0)=0$. We have the following theorem [11, Theorem 2] for a uniformly convex Banach space.

Theorem 2.1 (Xu [11]). E is a uniformly convex Banach space if and only if, for every bounded subset $B$ of $E$, there exists $g_{B} \in G$ such that

$$
\|\lambda x+(1-\lambda) y\|^{2} \leq \lambda\|x\|^{2}+(1-\lambda)\|y\|^{2}-\lambda(1-\lambda) g_{B}(\|x-y\|)
$$

for all $x, y \in B$ and $0 \leq \lambda \leq 1$.

Bruck [12] proved the following result for nonexpansive mappings. 
Theorem 2.2 (Bruck [12]). Let C be a bounded closed convex subset of a uniformly convex Banach space $E$. Then, there exists $\gamma \in G$ such that

$$
r\left(\left\|T\left(\sum_{i=1}^{n} \lambda_{i} x_{i}\right)-\sum_{i=1}^{n} \lambda_{i} T x_{i}\right\|\right) \leq \max _{1 \leq j<k \leq n}\left(\left\|x_{j}-x_{k}\right\|-\left\|T x_{j}-T x_{k}\right\|\right)
$$

for all $n \in \mathbb{N},\left\{x_{1}, x_{2}, \ldots, x_{n}\right\} \subset C,\left\{\lambda_{1}, \lambda_{2}, \ldots, \lambda_{n}\right\} \subset[0,1]$ with $\sum_{i=1}^{n} \lambda_{i}=1$ and nonexpansive mapping $T$ of $C$ into $E$.

Let $\left\{C_{n}\right\}$ be a sequence of nonempty closed convex subsets of a reflexive Banach space $E$. We denote the set of all strong limit points of $\left\{C_{n}\right\}$ by s- $-\mathrm{Li}_{n} C_{n}$, that is, $x \in \mathrm{s}-\mathrm{Li}_{n} C_{n}$ if and only if there exists $\left\{x_{n}\right\} \subset E$ such that $\left\{x_{n}\right\}$ converges strongly to $x$ and that $x_{n} \in C_{n}$ for all $n \in \mathbb{N}$. Similarly the set of all weak subsequential limit points by $\mathrm{w}-\mathrm{Ls}_{n} C_{n} ; y \in \mathrm{w}-\mathrm{Ls}_{n} C_{n}$ if and only if there exist a subsequence $\left\{C_{n_{i}}\right\}$ of $\left\{C_{n}\right\}$ and a sequence $\left\{y_{i}\right\} \subset E$ such that $\left\{y_{i}\right\}$ converges weakly to $y$ and that $y_{i} \in C_{n_{i}}$ for all $i \in \mathbb{N}$. If $C_{0}$ satisfies that $C_{0}=\mathrm{s}-\mathrm{Li}_{n} C_{n}=$ w-Ls $C_{n} C_{n}$, then we say that $\left\{C_{n}\right\}$ converges to $C_{0}$ in the sense of Mosco and we write $C_{0}=$ $\mathrm{M}-\lim _{n} C_{n}$. By definition, it always holds that $\mathrm{s}-\mathrm{Li}_{n} C_{n} \subset \mathrm{w}-\mathrm{Ls}_{n} C_{n}$. Therefore, to prove $C_{0}=$ M- $\lim _{n} C_{n}$, it suffices to show that

$$
\mathrm{w}-\mathrm{Ls}_{n} C_{n} \subset C_{0} \subset \mathrm{s}-\mathrm{Li}_{n} C_{n}
$$

One of the simplest examples of Mosco convergence is a decreasing sequence $\left\{C_{n}\right\}$ with respect to inclusion. The Mosco limit of such a sequence is $\bigcap_{n=1}^{\infty} C_{n}$. For more details, see [13].

Suppose that $E$ is smooth, strictly convex, and reflexive. The normalized duality mapping of $E$ is denoted by $J$, that is,

$$
J x=\left\{x^{*} \in E^{*}:\|x\|^{2}=\left\langle x, x^{*}\right\rangle=\left\|x^{*}\right\|^{2}\right\}
$$

for $x \in E$. In this setting, we may show that $J$ is a single-valued one-to-one mapping onto $E^{*}$. For more details, see [14-16].

Let $C$ be a nonempty closed convex subset of a strictly convex and reflexive Banach space $E$. Then, for an arbitrarily fixed $x \in E$, a function $C \ni y \mapsto\|y-x\|^{2} \in \mathbb{R}$ has a unique minimizer $y_{x} \in C$. Using such a point, we define the metric projection $P_{C}: E \rightarrow C$ by $P_{C} x=$ $y_{x}$ for every $x \in E$. The metric projection has the following important property: $x_{0}=P_{C} x$ if and only if $x_{0} \in C$ and $\left\langle x_{0}-z, J\left(x-x_{0}\right)\right\rangle \geq 0$ for all $z \in C$.

In the same manner, we define the generalized projection [17] $\Pi_{C}: E \rightarrow C$ for a nonempty closed convex subset $C$ of a strictly convex, smooth, and reflexive Banach space $E$ as follows. For a fixed $x \in E$, a function $C \ni y \mapsto\|y\|^{2}-2\langle y, J(x)\rangle+\|x\|^{2} \in \mathbb{R}$ has a unique minimizer and we define $\Pi_{C} x$ by this point. We know that the following characterization holds for the generalized projection [17, 18]: $x_{0}=\Pi_{C} x$ if and only if $x_{0} \in C$ and $\left\langle x_{0}-z, J x-\right.$ $\left.J x_{0}\right\rangle \geq 0$ for all $z \in C$.

Tsukada [19] proved the following theorem for a sequence of metric projections in a Banach space.

Theorem 2.3 (Tsukada [19]). Let $E$ be a reflexive and strictly convex Banach space and let $\left\{C_{n}\right\}$ be a sequence of nonempty closed convex subsets of $E$. If $C_{0}=\mathrm{M}-\lim _{n} C_{n}$ exists and nonempty, then, 
for each $x \in E,\left\{P_{C_{n}} x\right\}$ converges weakly to $P_{C_{0}} x$, where $P_{K}$ is the metric projection onto a nonempty closed convex subset $K$ of $E$. Moreover, if $E$ has the Kadec-Klee property, the convergence is in the strong topology.

On the other hand, Ibaraki et al. [20] proved the following theorem for a sequence of generalized projections in a Banach space.

Theorem 2.4 (Ibaraki et al. [20]). Let E be a strictly convex, smooth, and reflexive Banach space and let $\left\{C_{n}\right\}$ be a sequence of nonempty closed convex subsets of $E$. If $C_{0}=\mathrm{M}-\lim _{n} C_{n}$ exists and nonempty, then, for each $x \in E,\left\{\Pi_{C_{n}} x\right\}$ converges weakly to $\Pi_{C_{0}} x$, where $\Pi_{K}$ is the generalized projection onto a nonempty closed convex subset $K$ of $E$. Moreover, if $E$ has the Kadec-Klee property, the convergence is in the strong topology.

Kimura [21] obtained the further generalization of this theorem by using the Bregman projection; see also [22].

Theorem 2.5 (Kimura [21]). Let $C$ be a nonempty closed convex subset of a reflexive Banach space $E$ and let $f: E \rightarrow(-\infty, \infty]$ be a Bregman function on $C$; that is, (i) $f$ is lower semicontinuous and strictly convex; (ii) $C$ is contained by the interior of the domain of $f$; (iii) $f$ is Gateaux differentiable on $C$; (iv) the subsets $\left\{u \in C: D_{f}(y, u) \leq \alpha\right\}$ and $\left\{v \in C: D_{f}(v, x) \leq \alpha\right\}$ of $C$ are both bounded for all $x, y \in C$ and $\alpha \geq 0$, where $D_{f}(y, x)=f(y)-f(x)+\langle\nabla f(x), x-y\rangle$ for all $y \in D$ and $x \in C$. Let $\left\{C_{n}\right\}$ be a sequence of nonempty closed convex subsets of $C$ such that $C_{0}=\mathrm{M}-\lim _{n} C_{n}$ exists and is nonempty. Suppose that $f$ is sequentially consistent; that is, for any bounded sequence $\left\{x_{n}\right\}$ of $C$ and $\left\{y_{n}\right\}$ of the domain of $f, \lim _{n \rightarrow \infty} D_{f}\left(y_{n}, x_{n}\right)=0$ implies $\lim _{n \rightarrow \infty}\left\|y_{n}-x_{n}\right\|=0$. Then, the sequence $\left\{\Pi_{C_{n}}^{f} x\right\}$ of Bregman projections converges strongly to $\Pi_{C_{0}}^{f} x$ for all $x \in C$.

We note that the generalized duality mapping $J$ coincides with $\nabla f$ if the function $f$ is defined by $f(x)=\|x\|^{2} / 2$ for $x \in E$. In this case, the Bregman projection $\Pi_{K}^{f}$ with respect to $f$ becomes the generalized projection $\Pi_{K}$ for any nonempty closed convex subset $K$ of $E$.

\section{Main Results}

Let $C$ be a nonempty closed convex subset of $E$ and let $\left\{T_{n}\right\}$ be a sequence of mappings of $C$ into itself such that $F=\bigcap_{n=1}^{\infty} F\left(T_{n}\right) \neq \emptyset$. We consider the following conditions.

(I) For every bounded sequence $\left\{z_{n}\right\}$ in $C, \lim _{n \rightarrow \infty}\left\|z_{n}-T_{n} z_{n}\right\|=0$ implies $\omega_{w}\left(z_{n}\right) \subset F$, where $\omega_{w}\left(z_{n}\right)$ is the set of all weak cluster points of $\left\{z_{n}\right\}$; see [23-25].

(II) for every sequence $\left\{z_{n}\right\}$ in $C$ and $z \in C, z_{n} \rightarrow z$ and $T_{n} z_{n} \rightarrow z$ imply $z \in F$.

We know that condition (I) implies condition (II). Then, we have the following results.

Theorem 3.1. Let $C$ be a nonempty bounded closed convex subset of a uniformly convex Banach space $E$ and let $\left\{T_{n}\right\}$ be a family of nonexpansive mappings of $C$ into itself with $F=\bigcap_{n=1}^{\infty} F\left(T_{n}\right) \neq \emptyset$. Let $C_{n}\left(t_{n}\right)=$ clco $\left\{z \in C:\left\|z-T_{n} z\right\| \leq t_{n}\right\}$ for each $n \in \mathbb{N}$, where $\left\{t_{n}\right\} \subset[0, \infty)$. Then, the following are equivalent:

(i) $\left\{T_{n}\right\}$ satisfies condition (I);

(ii) for every $\left\{t_{n}\right\} \subset[0, \infty)$ with $t_{n} \rightarrow 0$ as $n \rightarrow \infty, \mathrm{M}-\lim _{n} C_{n}\left(t_{n}\right)=F$. 
Proof. First, let us prove that (i) implies (ii). Let $\left\{t_{n}\right\} \subset[0, \infty)$ with $t_{n} \rightarrow 0$ as $n \rightarrow \infty$. It is obvious that $F \subset C_{n}\left(t_{n}\right)$ and $C_{n}\left(t_{n}\right)$ is closed and convex for all $n \in \mathbb{N}$. Thus we have

$$
F \subset \mathrm{s}-\operatorname{Li}_{n} C_{n}\left(t_{n}\right)
$$

Let $z \in \mathrm{w}-\operatorname{Ls}_{n} C_{n}\left(t_{n}\right)$. Then, there exists a sequence $\left\{z_{i}\right\}$ such that $z_{i} \in C_{n_{i}}\left(t_{n_{i}}\right)$ for all $i \in \mathbb{N}$ and $z_{i} \rightarrow z$ as $i \rightarrow \infty$. Let $\left\{u_{n}\right\}$ be a sequence in $C$ such that $u_{n} \in C_{n}\left(t_{n}\right)$ for every $n \in \mathbb{N}$ and that $u_{n_{i}}=z_{i}$ for all $i \in \mathbb{N}$. Fix $n \in \mathbb{N}$. From the definition of $C_{n}\left(t_{n}\right)$, there exist $m \in \mathbb{N}$, $\left\{\lambda_{1}, \lambda_{2}, \ldots, \lambda_{m}\right\} \subset[0,1]$, and $\left\{y_{1}, y_{2}, \ldots, y_{m}\right\} \subset C$ such that

$$
\sum_{i=1}^{m} \lambda_{i}=1, \quad\left\|u_{n}-\sum_{i=1}^{m} \lambda_{i} y_{i}\right\|<t_{n}, \quad\left\|y_{i}-T_{n} y_{i}\right\| \leq t_{n}
$$

for each $i=1,2, \ldots, m$. On the other hand, by Theorem 2.2 , there exists a strictly increasing continuous convex function $\gamma:[0, \infty) \rightarrow[0, \infty)$ with $\gamma(0)=0$ such that

$$
r\left(\left\|T\left(\sum_{i=1}^{n} \lambda_{i} x_{i}\right)-\sum_{i=1}^{n} \lambda_{i} T x_{i}\right\|\right) \leq \max _{1 \leq j<k \leq n}\left(\left\|x_{j}-x_{k}\right\|-\left\|T x_{j}-T x_{k}\right\|\right)
$$

for all $n \in \mathbb{N},\left\{x_{1}, x_{2}, \ldots, x_{n}\right\} \subset C,\left\{\lambda_{1}, \lambda_{2}, \ldots, \lambda_{n}\right\} \subset[0,1]$ with $\sum_{i=1}^{n} \lambda_{i}=1$ and nonexpansive mapping $T$ of $C$ into $E$. Thus we get

$$
\begin{aligned}
\left\|u_{n}-T_{n} u_{n}\right\| \leq & \left\|u_{n}-\sum_{i=1}^{m} \lambda_{i} y_{i}\right\|+\left\|\sum_{i=1}^{m} \lambda_{i} y_{i}-\sum_{i=1}^{m} \lambda_{i} T_{n} y_{i}\right\| \\
& +\left\|\sum_{i=1}^{m} \lambda_{i} T_{n} y_{i}-T_{n}\left(\sum_{i=1}^{m} \lambda_{i} y_{i}\right)\right\|+\left\|T_{n}\left(\sum_{i=1}^{m} \lambda_{i} y_{i}\right)-T_{n} u_{n}\right\| \\
\leq & 3 t_{n}+\gamma^{-1}\left(\max _{1 \leq j<k \leq m}\left(\left\|y_{j}-y_{k}\right\|-\left\|T_{n} y_{j}-T_{n} y_{k}\right\|\right)\right) \\
\leq & 3 t_{n}+\gamma^{-1}\left(\max _{1 \leq j<k \leq m}\left(\left\|y_{j}-T_{n} y_{j}\right\|+\left\|y_{k}-T_{n} y_{k}\right\|\right)\right) \\
& \leq 3 t_{n}+\gamma^{-1}\left(2 t_{n}\right)
\end{aligned}
$$

for every $n \in \mathbb{N}$, which implies $\left\|u_{n}-T_{n} u_{n}\right\| \rightarrow 0$ as $n \rightarrow \infty$. From condition (I), we get $z \in \omega_{w}\left(z_{i}\right) \subset \omega_{w}\left(u_{n}\right) \subset F$, that is,

$$
\mathrm{W}-\operatorname{Ls}_{n} C_{n}\left(t_{n}\right) \subset F
$$

By (3.1) and (3.5), we have

$$
\mathrm{M}-\lim _{n} C_{n}\left(t_{n}\right)=F
$$


Next we show that (ii) implies (i). Let $\left\{z_{n}\right\}$ be a sequence in $C$ such that

$$
\lim _{n \rightarrow \infty}\left\|z_{n}-T_{n} z_{n}\right\|=0
$$

and define $\left\{t_{n}\right\}$ by $t_{n}=\left\|z_{n}-T_{n} z_{n}\right\|$ for each $n \in \mathbb{N}$. Suppose that a subsequence $\left\{z_{n_{k}}\right\}$ of $\left\{z_{n}\right\}$ converges weakly to $z$. Then since $z_{n} \in C_{n}\left(t_{n}\right)$ for all $n \in \mathbb{N}$ and M- $\lim _{n} C_{n}\left(t_{n}\right)=F$, we have $z \in F$; that is, condition (I) holds.

For a sequence of mappings satisfying condition (II), we have the following characterization.

Theorem 3.2. Let $C$ be a nonempty bounded closed convex subset of a uniformly convex Banach space $E$ and let $\left\{T_{n}\right\}$ be a family of nonexpansive mappings of $C$ into itself with $F=\bigcap_{n=1}^{\infty} F\left(T_{n}\right) \neq \emptyset$. Let $D_{0}\left(t_{0}\right)=C$ and $D_{n}\left(t_{n}\right)=$ clco $\left\{z \in D_{n-1}\left(t_{n-1}\right):\left\|z-T_{n} z\right\| \leq t_{n}\right\}$ for each $n \in \mathbb{N}$, where $\left\{t_{n}\right\} \subset[0, \infty)$. Then, the following are equivalent:

(i) $\left\{T_{n}\right\}$ satisfies condition (II);

(ii) for every $\left\{t_{n}\right\} \subset[0, \infty)$ with $t_{n} \rightarrow 0$ as $n \rightarrow \infty, \mathrm{M}-\lim _{n} D_{n}\left(t_{n}\right)=F$.

Proof. Let us show that (i) implies (ii). Let $\left\{t_{n}\right\} \subset[0, \infty)$ with $t_{n} \rightarrow 0$ as $n \rightarrow \infty$. We have $F \subset D_{n}\left(t_{n}\right) \subset D_{n-1}\left(t_{n-1}\right)$ for all $n \in \mathbb{N}$. Thus we get

$$
F \subset \bigcap_{n=0}^{\infty} D_{n}\left(t_{n}\right)=\mathrm{M}-\lim _{n} D_{n}\left(t_{n}\right)
$$

Let $z \in \bigcap_{n=0}^{\infty} D_{n}\left(t_{n}\right)$. We have $z \in D_{n}\left(t_{n}\right)$ for all $n \in \mathbb{N}$. As in the proof of Theorem 3.1, we get $\lim _{n \rightarrow \infty}\left\|z-T_{n} z\right\|=0$. By condition (II), we obtain $z \in F$, which implies $\bigcap_{n=0}^{\infty} D_{n}\left(t_{n}\right) \subset F$. Hence we have $\mathrm{M}-\lim _{n} D_{n}\left(t_{n}\right)=F$.

Suppose that condition (ii) holds. Let $\left\{z_{n}\right\}$ be a sequence in $C$ and $z \in C$ such that $z_{n} \rightarrow z$ and that $T_{n} z_{n} \rightarrow z$. Since

$$
\begin{aligned}
\left\|z-T_{n} z\right\| & \leq\left\|z-z_{n}\right\|+\left\|z_{n}-T_{n} z_{n}\right\|+\left\|T_{n} z_{n}-T_{n} z\right\| \\
& \leq 2\left\|z_{n}-z\right\|+\left\|z_{n}-T_{n} z_{n}\right\|
\end{aligned}
$$

for each $n \in \mathbb{N}$, we have $\lim _{n \rightarrow \infty}\left\|z-T_{n} z\right\|=0$. Letting $t_{n}=\left\|z-T_{n} z\right\|$ for each $n \in \mathbb{N}$, we have $z \in D_{n}\left(t_{n}\right)$ for every $n \in \mathbb{N}$ and $t_{n} \rightarrow 0$ as $n \rightarrow \infty$, which implies $z \in \mathrm{M}$ - $\lim _{n} D_{n}\left(t_{n}\right)=F$. Hence (i) holds, which is the desired result.

Remark 3.3. In Theorem 3.2, it is obvious by definition that $\left\{D_{n}\left(t_{n}\right)\right\}$ is a decreasing sequence with respect to inclusion. Therefore, conditions (i) and (ii) are also equivalent to

(ii') for every $\left\{t_{n}\right\} \subset[0, \infty)$ with $t_{n} \rightarrow 0$ as $n \rightarrow \infty$, PK- $\lim _{n} D_{n}\left(t_{n}\right)=F$,

where PK- $\lim _{n} D_{n}\left(t_{n}\right)$ is the Painlevé-Kuratowski limit of $\left\{D_{n}\left(t_{n}\right)\right\}$; see, for example, [13] for more details. 
In the next section, we will see various types of sequences of nonexpansive mappings which satisfy conditions (I) and (II).

\section{The Sequences of Mappings Satisfying Conditions (I) and (II)}

First let us show some known results which play important roles for our results.

Theorem 4.1 (Browder [1]). Let $C$ be a nonempty closed convex subset of a uniformly convex Banach space $E$ and $T$ a nonexpansive mapping on $C$ with $F(T) \neq \emptyset$. If $\left\{x_{n}\right\}$ converges weakly to $z \in C$ and $\left\{x_{n}-T x_{n}\right\}$ converges strongly to 0 , then $z$ is a fixed point of $T$.

Theorem 4.2 (Bruck [26]). Let $C$ be a nonempty closed convex subset of a strictly convex Banach space $E$ and $T_{k}: C \rightarrow C$ a nonexpansive mapping for each $k \in \mathbb{N}$. Let $\left\{\beta_{k}\right\}$ be a sequence of positive real numbers such that $\sum_{k=1}^{\infty} \beta_{k}=1$. If $\bigcap_{k=1}^{\infty} F\left(T_{k}\right)$ is nonempty, then the mapping $T=\sum_{k=1}^{\infty} \beta_{k} T_{k}$ is well defined and

$$
F(T)=\bigcap_{k=1}^{\infty} F\left(T_{k}\right)
$$

Theorems 4.3, 4.5(i), 4.6-4.9 show the examples of a family of nonexpansive mappings satisfying condition (I). Theorems 4.5(ii), 4.11, and 4.12 show those satisfying condition (II).

Theorem 4.3. Let $C$ be a nonempty closed convex subset of a uniformly convex Banach space $E$ and let $T$ be a nonexpansive mapping of $C$ into itself with $F(T) \neq \emptyset$. Let $T_{n}=T$ for all $n \in \mathbb{N}$. Then, $\left\{T_{n}\right\}$ is a family of nonexpansive mappings of $C$ into itself with $\bigcap_{n=1}^{\infty} F\left(T_{n}\right)=F(T)$ and satisfies condition (I).

Proof. This is a direct consequence of Theorem 4.1.

Remark 4.4. In the previous theorem, if $C$ is bounded, then $F(T)$ is guaranteed to be nonempty by Kirk's fixed point theorem [27].

Let $E$ be a Banach space and $A$ a set-valued operator on $E$. $A$ is called an accretive operator if $\left\|x_{1}-x_{2}\right\| \leq\left\|\left(x_{1}-x_{2}\right)+\lambda\left(y_{1}-y_{2}\right)\right\|$ for every $\lambda>0$ and $x_{1}, x_{2}, y_{1}, y_{2} \in E$ with $y_{1} \in A x_{1}$ and $y_{2} \in A x_{2}$.

Let $A$ be an accretive operator and $r>0$. We know that the operator $I+r A$ has a single-valued inverse, where $I$ is the identity operator on $E$. We call $(I+r A)^{-1}$ the resolvent of $A$ and denote it by $J_{r}$. We also know that $J_{r}$ is a nonexpansive mapping with $F\left(J_{r}\right)=A^{-1} 0$ for any $r>0$, where $A^{-1} 0=\{z \in E: 0 \in A z\}$. For more details, see, for example, [15].

We have the following result for the resolvents of an accretive operator by [25]; see also [15, Theorem 4.6.3], and [16, Theorem 3.4.3] .

Theorem 4.5. Let $C$ be a nonempty closed convex subset of a uniformly convex Banach space $E$ and let $A \subset E \times E$ be an accretive operator with $\mathrm{cl} D(A) \subset C \subset \bigcap_{r>0} R(I+r A)$ and $A^{-1} 0 \neq \emptyset$. Let $T_{n}=J_{r_{n}}$ for every $n \in \mathbb{N}$, where $r_{n}>0$ for all $n \in \mathbb{N}$. Then, $\left\{T_{n}\right\}$ is a family of nonexpansive mappings of $C$ 
into itself with $\bigcap_{n=1}^{\infty} F\left(T_{n}\right)=A^{-1} 0$ and the following hold:

(i) if $\inf _{n \in \mathbb{N}} r_{n}>0$, then $\left\{T_{n}\right\}$ satisfies condition (I),

(ii) if there exists a subsequence $\left\{r_{n_{i}}\right\}$ of $\left\{r_{n}\right\}$ such that $\inf _{i \in \mathbb{N}} r_{n_{i}}>0$, then $\left\{T_{n}\right\}$ satisfies condition (II).

Proof. It is obvious that $T_{n}$ is a nonexpansive mapping of $C$ into itself and $F\left(T_{n}\right)=A^{-1} 0$ for all $n \in \mathbb{N}$.

For (i), suppose $\inf _{n \in \mathbb{N}} r_{n}>0$ and let $\left\{z_{n}\right\}$ be a bounded sequence in $C$ such that $\lim _{n \rightarrow \infty}\left\|z_{n}-T_{n} z_{n}\right\|=0$. By [25, Lemma 3.5], we have $\lim _{n \rightarrow \infty}\left\|z_{n}-J_{1} z_{n}\right\|=0$. Using Theorem 4.1 we obtain $\omega_{w}\left(z_{n}\right) \subset F\left(J_{1}\right)=A^{-1} 0$.

Let us show (ii). Let $\left\{r_{n_{i}}\right\}$ be a subsequence of $\left\{r_{n}\right\}$ with $\inf _{i \in \mathbb{N}} r_{n_{i}}>0$ and let $\left\{z_{n}\right\}$ be a sequence in $C$ and $z \in C$ such that $z_{n} \rightarrow z$ and $T_{n} z_{n} \rightarrow z$. As in the proof of (i), we get $\lim _{i \rightarrow \infty}\left\|z_{n_{i}}-J_{1} z_{n_{i}}\right\|=0$ and $z \in A^{-1} 0$.

Let $C$ be a nonempty closed convex subset of $E$. Let $\left\{S_{n}\right\}$ be a family of mappings of $C$ into itself and let $\left\{\beta_{n, k}: n, k \in \mathbb{N}, 1 \leq k \leq n\right\}$ be a sequence of real numbers such that $0 \leq \beta_{i, j} \leq 1$ for every $i, j \in \mathbb{N}$ with $i \geq j$. Takahashi $[16,28]$ introduced a mapping $W_{n}$ of $C$ into itself for each $n \in \mathbb{N}$ as follows:

$$
\begin{gathered}
U_{n, n}=\beta_{n, n} S_{n}+\left(1-\beta_{n, n}\right) I, \\
U_{n, n-1}=\beta_{n, n-1} S_{n-1} U_{n, n}+\left(1-\beta_{n, n-1}\right) I, \\
\vdots \\
U_{n, k}=\beta_{n, k} S_{k} U_{n, k+1}+\left(1-\beta_{n, k}\right) I, \\
\vdots \\
U_{n, 2}=\beta_{n, 2} S_{2} U_{n, 3}+\left(1-\beta_{n, 2}\right) I, \\
W_{n}=U_{n, 1}=\beta_{n, 1} S_{1} U_{n, 2}+\left(1-\beta_{n, 1}\right) I .
\end{gathered}
$$

Such a mapping $W_{n}$ is called the W-mapping generated by $S_{n}, S_{n-1}, \ldots, S_{1}$ and $\beta_{n, n}, \beta_{n, n-1}$, $\ldots, \beta_{n, 1}$. We have the following result for the W-mapping by $[29,30]$; see also [25, Lemma 3.6].

Theorem 4.6. Let $C$ be a nonempty closed convex subset of a uniformly convex Banach space $E$ and let $\left\{S_{n}\right\}$ be a family of nonexpansive mappings of $C$ into itself with $F=\bigcap_{n=1}^{\infty} F\left(S_{n}\right) \neq \emptyset$. Let $\left\{\beta_{n, k}\right.$ : $n, k \in \mathbb{N}, 1 \leq k \leq n\}$ be a sequence of real numbers such that $0<a \leq \beta_{i, j} \leq b<1$ for every $i, j \in \mathbb{N}$ with $i \geq j$ and let $W_{n}$ be the $W$-mapping generated by $S_{n}, S_{n-1}, \ldots, S_{1}$ and $\beta_{n, n}, \beta_{n, n-1}, \ldots, \beta_{n, 1}$. Let $T_{n}=W_{n}$ for every $n \in \mathbb{N}$. Then, $\left\{T_{n}\right\}$ is a family of nonexpansive mappings of $C$ into itself with $\bigcap_{n=1}^{\infty} F\left(T_{n}\right)=F$ and satisfies condition (I).

Proof. It is obvious that $\left\{T_{n}\right\}$ is a family of nonexpansive mappings of $C$ into itself. By [29, Lemma 3.1], $F\left(T_{n}\right)=\bigcap_{i=1}^{n} F\left(S_{i}\right)$ for all $n \in \mathbb{N}$, which implies $\bigcap_{n=1}^{\infty} F\left(T_{n}\right)=F$. Let $\left\{z_{n}\right\}$ be a bounded sequence in $C$ such that $\lim _{n \rightarrow \infty}\left\|z_{n}-T_{n} z_{n}\right\|=0$. We have $\lim _{n \rightarrow \infty}\left\|z_{n}-S_{1} U_{n, 2} z_{n}\right\|=0$. 
Let $z \in F$. From Theorem 2.1, for a bounded subset $B$ of $C$ containing $\left\{z_{n}\right\}$ and $z$, there exists $g_{B_{0}} \in G$, where $B_{0}=\left\{y \in E:\|y\| \leq 2 \sup _{x \in B}\|x\|\right\}$, such that

$$
\begin{aligned}
\left\|z_{n}-z\right\|^{2} \leq & \left(\left\|z_{n}-S_{1} U_{n, 2} z_{n}\right\|+\left\|S_{1} U_{n, 2} z_{n}-z\right\|\right)^{2} \\
= & \left\|z_{n}-S_{1} U_{n, 2} z_{n}\right\|\left(\left\|z_{n}-S_{1} U_{n, 2} z_{n}\right\|+2\left\|S_{1} U_{n, 2} z_{n}-z\right\|\right) \\
& +\left\|S_{1} U_{n, 2} z_{n}-z\right\|^{2} \\
\leq & M\left\|z_{n}-S_{1} U_{n, 2} z_{n}\right\|+\left\|U_{n, 2} z_{n}-z\right\|^{2} \\
\leq & M\left\|z_{n}-S_{1} U_{n, 2} z_{n}\right\|+\beta_{n, 2}\left\|S_{2} U_{n, 3} z_{n}-z\right\|^{2}+\left(1-\beta_{n, 2}\right)\left\|z_{n}-z\right\|^{2} \\
& -\beta_{n, 2}\left(1-\beta_{n, 2}\right) g_{B_{0}}\left(\left\|S_{2} U_{n, 3} z_{n}-z_{n}\right\|\right) \\
\leq & M\left\|z_{n}-S_{1} U_{n, 2} z_{n}\right\|+\left\|z_{n}-z\right\|^{2}-\beta_{n, 2}\left(1-\beta_{n, 2}\right) g_{B_{0}}\left(\left\|S_{2} U_{n, 3} z_{n}-z_{n}\right\|\right)
\end{aligned}
$$

for every $n \in \mathbb{N}$, where $M=\sup _{n \in \mathbb{N}}\left(\left\|z_{n}-S_{1} U_{n, 2} z_{n}\right\|+2\left\|S_{1} U_{n, 2} z_{n}-z\right\|\right)$. Thus we obtain $\lim _{n \rightarrow \infty}\left\|S_{2} U_{n, 3} z_{n}-z_{n}\right\|=0$. Let $m \in \mathbb{N}$. Similarly, we have

$$
\lim _{n \rightarrow \infty}\left\|S_{m} U_{n, m+1} z_{n}-z_{n}\right\|=\lim _{n \rightarrow \infty}\left\|S_{m+1} U_{n, \mathrm{~m}+2} z_{n}-z_{n}\right\|=0
$$

As in the proof of [30, Theorem 3.1], we get $\lim _{n \rightarrow \infty}\left\|z_{n}-S_{k} z_{n}\right\|=0$ for each $k \in \mathbb{N}$. Using Theorem 4.1 we obtain $\omega_{w}\left(z_{n}\right) \subset F$.

We have the following result for a convex combination of nonexpansive mappings which Aoyama et al. [31] proposed.

Theorem 4.7. Let $C$ be a nonempty closed convex subset of a uniformly convex Banach space $E$ and let $\left\{S_{n}\right\}$ be a family of nonexpansive mappings of $C$ into itself such that $F=\bigcap_{n=1}^{\infty} F\left(S_{n}\right) \neq \emptyset$. Let $\left\{\beta_{n}^{k}\right\}$ be a family of nonnegative numbers with indices $n, k \in \mathbb{N}$ with $k \leq n$ such that

(i) $\sum_{k=1}^{n} \beta_{n}^{k}=1$ for every $n \in \mathbb{N}$,

(ii) $\lim _{n \rightarrow \infty} \beta_{n}^{k}>0$ for each $k \in \mathbb{N}$,

and let $T_{n}=\alpha_{n} I+\left(1-\alpha_{n}\right) \sum_{k=1}^{n} \beta_{n}^{k} S_{k}$ for all $n \in \mathbb{N}$, where $\left\{\alpha_{n}\right\} \subset[a, b]$ for some $a, b \in(0,1)$ with $a \leq b$. Then, $\left\{T_{n}\right\}$ is a family of nonexpansive mappings of $C$ into itself with $\bigcap_{n=1}^{\infty} F\left(T_{n}\right)=F$ and satisfies condition (I).

Proof. It is obvious that $\left\{T_{n}\right\}$ is a family of nonexpansive mappings of $C$ into itself. By Theorem 4.2, we have $F\left(\sum_{k=1}^{n} \beta_{n}^{k} S_{k}\right)=\bigcap_{k=1}^{n} F\left(S_{k}\right)$ and thus $F\left(T_{n}\right)=\bigcap_{k=1}^{n} F\left(S_{k}\right)$. It follows that

$$
F=\bigcap_{n=1}^{\infty} F\left(S_{n}\right)=\bigcap_{n=1}^{\infty} \bigcap_{k=1}^{n} F\left(S_{k}\right)=\bigcap_{n=1}^{\infty} F\left(T_{n}\right)
$$


Let $\left\{z_{n}\right\}$ be a bounded sequence in $C$ such that $\lim _{n \rightarrow \infty}\left\|z_{n}-T_{n} z_{n}\right\|=0$. Let $z \in F, m \in \mathbb{N}$, and $\gamma_{n}^{m}=\alpha_{n}+\left(1-\alpha_{n}\right) \beta_{n}^{m}$ for $n \in \mathbb{N}$. By Theorem 2.1, for a bounded subset $B$ of $C$ containing $\left\{z_{n}\right\}$ and $z$, there exists $g_{B_{0}} \in G$ with $B_{0}=\left\{y \in E:\|y\| \leq 2 \sup _{x \in B}\|x\|\right\}$ which satisfies that

$$
\begin{aligned}
\left\|z_{n}-z\right\|^{2} \leq & \left(\left\|z_{n}-T_{n} z_{n}\right\|+\left\|T_{n} z_{n}-z\right\|\right)^{2} \leq M\left\|z_{n}-T_{n} z_{n}\right\|+\left\|T_{n} z_{n}-z\right\|^{2} \\
= & M\left\|z_{n}-T_{n} z_{n}\right\|+\left\|\alpha_{n}\left(z_{n}-z\right)+\left(1-\alpha_{n}\right) \sum_{k=1}^{n} \beta_{n}^{k}\left(S_{k} z_{n}-z\right)\right\|^{2} \\
\leq & M\left\|z_{n}-T_{n} z_{n}\right\|+\gamma_{n}^{m}\left\|\frac{\alpha_{n}\left(z_{n}-z\right)+\left(1-\alpha_{n}\right) \beta_{n}^{m}\left(S_{m} z_{n}-z\right)}{\gamma_{n}^{m}}\right\|^{2} \\
& +\left(1-\gamma_{n}^{m}\right)\left\|\frac{\left(1-\alpha_{n}\right)\left(\sum_{k=1}^{m-1} \beta_{n}^{k}\left(S_{k} z_{n}-z\right)+\sum_{k=m+1}^{n} \beta_{n}^{k}\left(S_{k} z_{n}-z\right)\right)}{1-\gamma_{n}^{m}}\right\|^{2} \\
\leq & M\left\|z_{n}-T_{n} z_{n}\right\|+\alpha_{n}\left\|z_{n}-z\right\|^{2}+\left(1-\alpha_{n}\right) \beta_{n}^{m}\left\|S_{m} z_{n}-z\right\|^{2} \\
& -\frac{\alpha_{n}\left(1-\alpha_{n}\right) \beta_{n}^{m}}{\gamma_{n}^{m}} g_{B_{0}}\left(\left\|z_{n}-S_{m} z_{n}\right\|\right)+\left(1-\gamma_{n}^{m}\right)\left\|z_{n}-z\right\|^{2} \\
= & M\left\|z_{n}-T_{n} z_{n}\right\|+\left\|z_{n}-z\right\|^{2}-\frac{\alpha_{n}\left(1-\alpha_{n}\right) \beta_{n}^{m}}{\alpha_{n}+\left(1-\alpha_{n}\right) \beta_{n}^{m}} g_{B_{0}}\left(\left\|z_{n}-S_{m} z_{n}\right\|\right)
\end{aligned}
$$

for $n \in \mathbb{N}$, where $M=\sup _{n \in \mathbb{N}}\left\{\left\|z_{n}-T_{n} z_{n}\right\|+2\left\|T_{n} z_{n}-z\right\|\right\}$. Since $a \leq \alpha_{n} \leq b$ for all $n \in \mathbb{N}$ and $\lim _{n \rightarrow \infty} \beta_{n}^{m}>0$, we get $\lim _{n \rightarrow \infty} \mathrm{g}_{B_{0}}\left(\left\|z_{n}-S_{m} z_{n}\right\|\right)=0$ and hence $\lim _{n \rightarrow \infty}\left\|z_{n}-S_{m} z_{n}\right\|=0$ for each $m \in \mathbb{N}$. Therefore, using Theorem 4.1 we obtain $\omega_{w}\left(z_{n}\right) \subset F$.

Let $C$ be a nonempty closed convex subset of a Banach space $E$ and let $S$ be a semigroup. A family $\mathcal{S}=\{T(t): t \in S\}$ is said to be a nonexpansive semigroup on $C$ if

(i) for each $t \in S, T(t)$ is a nonexpansive mapping of $C$ into itself;

(ii) $T(s t)=T(s) T(t)$ for every $s, t \in S$.

We denote by $F(\mathcal{S})$ the set of all common fixed points of $\mathcal{S}$, that is, $F(\mathcal{S})=\bigcap_{t \in S} F(T(t))$. We have the following result for nonexpansive semigroups by [25, Lemma 3.9]; see also [32, 33].

Theorem 4.8. Let $C$ be a nonempty closed convex subset of a uniformly convex Banach space $E$ and let $S$ be a semigroup. Let $\mathcal{S}=\{T(t): t \in S\}$ be a nonexpansive semigroup on $C$ such that $F(\mathcal{S}) \neq \emptyset$ and let $X$ be a subspace of $B(S)$ such that $X$ contains constants, $X$ is $l_{s}$-invariant (i.e., $\left.l_{s}(X) \subset X\right)$ for each $s \in S$, and the function $t \mapsto\left\langle T(t) x, x^{*}\right\rangle$ belongs to $X$ for every $x \in C$ and $x^{*} \in E^{*}$. Let $\left\{\mu_{n}\right\}$ be a sequence of means on $X$ such that $\left\|\mu_{n}-l_{s}^{*} \mu_{n}\right\| \rightarrow 0$ as $n \rightarrow \infty$ for all $s \in S$ and let $T_{n}=T_{\mu_{n}}$ for each $n \in \mathbb{N}$. Then, $\left\{T_{n}\right\}$ is a family of nonexpansive mappings of $C$ into itself with $\bigcap_{n=1}^{\infty} F\left(T_{n}\right)=F(\mathcal{S})$ and satisfies condition (I).

Proof. It is obvious that $\left\{T_{n}\right\}$ is a family of nonexpansive mappings of $C$ into itself. By [25, Lemma 3.9], we have $F(S)=\bigcap_{n=1}^{\infty} F\left(T_{n}\right)$. Let $\left\{z_{n}\right\}$ be a bounded sequence in $C$ such that $\lim _{n \rightarrow \infty}\left\|z_{n}-T_{n} z_{n}\right\|=0$. Then we get $\lim _{n \rightarrow \infty}\left\|z_{n}-T(t) z_{n}\right\|=0$ for every $t \in S$. Using Theorem 4.1 we have $\omega_{w}\left(z_{n}\right) \subset F(\mathcal{S})$. 
Let $C$ be a nonempty closed convex subset of a Banach space $E$. A family $\mathcal{S}=\{T(s)$ : $0 \leq s<\infty\}$ of mappings of $C$ into itself is called a one-parameter nonexpansive semigroup on $C$ if it satisfies the following conditions:

(i) $T(0) x=x$ for all $x \in C$;

(ii) $T(s+t)=T(s) T(t)$ for every $s, t \geq 0$;

(iii) $\|T(s) x-T(\mathrm{~s}) y\| \leq\|x-y\|$ for each $s \geq 0$ and $x, y \in C$;

(iv) for all $x \in C, s \mapsto T(s) x$ is continuous.

We have the following result for one-parameter nonexpansive semigroups by [25, Lemma 3.12].

Theorem 4.9. Let $C$ be a nonempty closed convex subset of a uniformly convex Banach space $E$ and let $\mathcal{S}=\{T(s): 0 \leq s<\infty\}$ be a one-parameter nonexpansive semigroup on $C$ with $F(\mathcal{S}) \neq \emptyset$. Let $\left\{r_{n}\right\} \subset(0, \infty)$ satisfy $\lim _{n \rightarrow \infty} r_{n}=\infty$ and let $T_{n}$ be a mapping such that

$$
T_{n} x=\frac{1}{r_{n}} \int_{0}^{r_{n}} T(s) x d s
$$

for all $x \in C$ and $n \in \mathbb{N}$. Then, $\left\{T_{n}\right\}$ is a family of nonexpansive mappings of $C$ into itself satisfying that $\bigcap_{n=1}^{\infty} F\left(T_{n}\right)=F(\mathcal{S})$ and condition (I).

Remark 4.10. If $C$ is bounded, then $F(S)$ is guaranteed to be nonempty; see [34].

Proof. It is obvious that $\left\{T_{n}\right\}$ is a family of nonexpansive mappings of $C$ into itself. By [25, Lemma 3.12], we have $F(S)=\bigcap_{n=1}^{\infty} F\left(T_{n}\right)$. Let $\left\{z_{n}\right\}$ be a bounded sequence in $C$ such that $\lim _{n \rightarrow \infty}\left\|z_{n}-T_{n} z_{n}\right\|=0$. We get $\lim _{n \rightarrow \infty}\left\|z_{n}-T(t) z_{n}\right\|=0$ for every $t \in S$. Hence, using Theorem 4.1 we have $\omega_{w}\left(z_{n}\right) \subset F(\mathcal{S})$. mappings.

Motivated by the idea of [23, page 256], we have the following result for nonexpansive

Theorem 4.11. Let $C$ be a nonempty closed convex subset of a uniformly convex Banach space $E$ and let I be a countable index set. Let $i: \mathbb{N} \rightarrow I$ be an index mapping such that, for all $j \in I$, there exist infinitely many $k \in \mathbb{N}$ satisfying $j=i(k)$. Let $\left\{S_{i}: i \in I\right\}$ be a family of nonexpansive mappings of $C$ into itself satisfying $F=\bigcap_{i \in I} F\left(S_{i}\right) \neq \emptyset$ and let $T_{n}=S_{i(n)}$ for all $n \in \mathbb{N}$. Then, $\left\{T_{n}\right\}$ is a family of nonexpansive mappings of $C$ into itself with $\bigcap_{n=1}^{\infty} F\left(T_{n}\right)=F$ and satisfies condition (II).

Proof. It is obvious that $\bigcap_{n=1}^{\infty} F\left(T_{n}\right)=F$. Let $\left\{z_{n}\right\}$ be a sequence in $C$ and $z \in C$ such that $z_{n} \rightarrow z$ and $T_{n} z_{n} \rightarrow z$. Fix $j \in I$. There exists a subsequence $\left\{i\left(n_{k}\right)\right\}$ of $\{i(n)\}$ such that $i\left(n_{k}\right)=j$ for all $k \in \mathbb{N}$. Thus we have $\lim _{k \rightarrow \infty}\left\|z_{n_{k}}-T_{n_{k}} z_{n_{k}}\right\|=\lim _{n \rightarrow \infty}\left\|z_{n_{k}}-S_{j} z_{n_{k}}\right\|=0$. Therefore, using Theorem $4.1 z \in F\left(S_{j}\right)$ for every $j \in I$ and hence we get $z \in F$.

From Theorem 4.11, we have the following result for one-parameter nonexpansive semigroups.

Theorem 4.12. Let $C$ be a nonempty closed convex subset of a uniformly convex Banach space $E$ and let $\mathcal{S}=\{T(t): 0 \leq t<\infty\}$ be a one-parameter nonexpansive semigroup on $C$ such that $F(\mathcal{S}) \neq \emptyset$. Let $S_{n}=T\left(r_{n}\right)$ for every $n \in \mathbb{N}$ with $\left\{r_{n}\right\} \subset(0, \infty)$ and $r_{n} \rightarrow 0$ as $n \rightarrow \infty$ and $T_{n}=S_{i(n)}$ for all $n \in \mathbb{N}$, where $i: \mathbb{N} \rightarrow \mathbb{N}$ is an index mapping satisfying, for all $j \in \mathbb{N}$, there exist infinitely many $k \in \mathbb{N}$ such that $j=i(k)$. Then, $\left\{T_{n}\right\}$ is a family of nonexpansive mappings of $C$ into itself with $\bigcap_{n=1}^{\infty} F\left(T_{n}\right)=F(\mathcal{S})$ and satisfies condition (II). 
Remark 4.13. If $C$ is bounded, it is guaranteed that $F(\mathcal{S}) \neq \emptyset$. See [34].

Proof. We have $\bigcap_{n=1}^{\infty} F\left(T_{n}\right)=F(\mathcal{S})$ by [35, Lemma 2.7]; see also [36]. By Theorem 4.11, we obtain the desired result.

\section{Strong Convergence Theorems}

Throughout this section, we assume that $C$ is a nonempty bounded closed convex subset of a uniformly convex Banach space $E$ and $\left\{T_{n}\right\}$ is a family of nonexpansive mappings of $C$ into itself with $F=\bigcap_{n=1}^{\infty} F\left(T_{n}\right) \neq \emptyset$. Then, we know that $F$ is closed and convex.

We get the following results for the metric projection by using Theorems 2.3, 3.1, and 3.2.

Theorem 5.1. Let $x \in E$ and let $\left\{x_{n}\right\}$ be a sequence generated by

$$
\begin{gathered}
C_{n}=\operatorname{clco}\left\{z \in C:\left\|z-T_{n} z\right\| \leq t_{n}\right\}, \\
x_{n}=P_{C_{n}} x
\end{gathered}
$$

for each $n \in \mathbb{N}$, where $\left\{t_{n}\right\} \subset(0, \infty)$ such that $t_{n} \rightarrow 0$ as $n \rightarrow \infty$, and $P_{C_{n}}$ is the metric projection onto $C_{n}$. If $\left\{T_{n}\right\}$ satisfies condition (I), then $\left\{x_{n}\right\}$ converges strongly to $P_{F} x$.

Theorem 5.2. Let $x \in E$ and let $\left\{y_{n}\right\}$ be a sequence generated by

$$
\begin{gathered}
C_{0}=C, \\
C_{n}=\operatorname{clco}\left\{z \in C_{n-1}:\left\|z-T_{n} z\right\| \leq t_{n}\right\}, \\
y_{n}=P_{C_{n}} x
\end{gathered}
$$

for each $n \in \mathbb{N}$, where $\left\{t_{n}\right\} \subset(0, \infty)$ such that $t_{n} \rightarrow 0$ as $n \rightarrow \infty$. If $\left\{T_{n}\right\}$ satisfies condition (II), then $\left\{y_{n}\right\}$ converges strongly to $P_{F} x$.

On the other hand, we have the following results for the Bregman projection by using Theorems 2.5, 3.1, and 3.2.

Theorem 5.3. Let $x \in C$ and let $f$ be a Bregman function on $C$ and let $f$ be sequentially consistent. Let $\left\{x_{n}\right\}$ be a sequence generated by

$$
\begin{gathered}
C_{n}=\operatorname{clco}\left\{z \in C:\left\|z-T_{n} z\right\| \leq t_{n}\right\}, \\
x_{n}=\Pi_{C_{n}}^{f} x
\end{gathered}
$$

for each $n \in \mathbb{N}$, where $\left\{t_{n}\right\} \subset(0, \infty)$ such that $t_{n} \rightarrow 0$ as $n \rightarrow \infty$ and $\Pi_{C_{n}}^{f}$ is the Bregman projection onto $C_{n}$. If $\left\{T_{n}\right\}$ satisfies condition $(I)$, then $\left\{x_{n}\right\}$ converges strongly to $\prod_{F}^{f} x$. 
Theorem 5.4. Let $x \in C$, let $f$ be a Bregman function on $C$, and let $f$ be sequentially consistent. Let $\left\{y_{n}\right\}$ be a sequence generated by

$$
\begin{gathered}
C_{0}=C, \\
C_{n}=\operatorname{clco}\left\{z \in C_{n-1}:\left\|z-T_{n} z\right\| \leq t_{n}\right\}, \\
y_{n}=\Pi_{C_{n}}^{f} x
\end{gathered}
$$

for each $n \in \mathbb{N}$, where $\left\{t_{n}\right\} \subset(0, \infty)$ such that $t_{n} \rightarrow 0$ as $n \rightarrow \infty$. If $\left\{T_{n}\right\}$ satisfies condition (II), then $\left\{y_{n}\right\}$ converges strongly to $\Pi_{F}^{f} x$.

In a similar fashion, we have the following results for the generalized projection by using Theorems 2.4, 3.1, and 3.2.

Theorem 5.5. Suppose that $E$ is smooth. Let $x \in E$ and let $\left\{x_{n}\right\}$ be a sequence generated by

$$
\begin{gathered}
C_{n}=\operatorname{clco}\left\{z \in C:\left\|z-T_{n} z\right\| \leq t_{n}\right\}, \\
x_{n}=\prod_{C_{n}} x
\end{gathered}
$$

for each $n \in \mathbb{N}$, where $\left\{t_{n}\right\} \subset(0, \infty)$ such that $t_{n} \rightarrow 0$ as $n \rightarrow \infty$ and $\Pi_{C_{n}}$ is the generalized projection onto $C_{n}$. If $\left\{T_{n}\right\}$ satisfies condition (I), then $\left\{x_{n}\right\}$ converges strongly to $\Pi_{F} x$.

Theorem 5.6. Suppose that $E$ is smooth. Let $x \in E$ and let $\left\{y_{n}\right\}$ be a sequence generated by

$$
\begin{gathered}
C_{0}=C, \\
C_{n}=\operatorname{clco}\left\{z \in C_{n-1}:\left\|z-T_{n} z\right\| \leq t_{n}\right\}, \\
y_{n}=\prod_{C_{n}} x
\end{gathered}
$$

for each $n \in \mathbb{N}$, where $\left\{t_{n}\right\} \subset(0, \infty)$ with $t_{n} \rightarrow 0$ as $n \rightarrow \infty$. If $\left\{T_{n}\right\}$ satisfies condition (II), then $\left\{y_{n}\right\}$ converges strongly to $\Pi_{F} x$.

Combining these theorems with the results shown in the previous section, we can obtain various types of convergence theorems for families of nonexpansive mappings.

\section{Generalization of Xu's and Matsushita-Takahashi's Theorems}

At the end of this paper, we remark the relationship between these results and the convergence theorems by $\mathrm{Xu}$ [9] and Matsushita and Takahashi [10] mentioned in the introduction.

Let us suppose the all assumptions in their results, respectively. Let $\left\{T_{n}\right\}$ be a countable family of nonexpansive mappings of $C$ into itself such that $\bigcap_{n=1}^{\infty} F\left(T_{n}\right) \neq \emptyset$ and suppose that it satisfies condition (I). Let us define $C_{n}=\operatorname{clco}\left\{z \in C:\left\|z-T_{n} z\right\| \leq t_{n}\left\|x_{n}-T_{n} x_{n}\right\|\right\}$ for $n \in \mathbb{N}$. 
Then, by definition, we have that $\bigcap_{k=1}^{\infty} F\left(T_{k}\right) \subset C_{n}$ for every $n \in \mathbb{N}$. On the other hand, we have

$$
\begin{gathered}
\left\langle\Pi_{C_{n} \cap D_{n}} x-z, J x-J \Pi_{C_{n} \cap D_{n}} x\right\rangle \geq 0, \\
\left\langle P_{C_{n} \cap D_{n}} x-z, J\left(x-P_{C_{n} \cap D_{n}} x\right)\right\rangle \geq 0
\end{gathered}
$$

for every $z \in C_{n} \cap D_{n}$ from basic properties of $P_{C_{n} \cap D_{n}}$ and $\Pi_{C_{n} \cap D_{n}}$. Therefore, for each theorem we have

$$
\bigcap_{k=1}^{\infty} F\left(T_{k}\right) \subset C_{n} \cap D_{n}
$$

for every $n \in \mathbb{N}$ by using mathematical induction. Since $C$ is bounded, a sequence $\left\{t_{n}\left\|x_{n}-T_{n} x_{n}\right\|\right\}$ converges to 0 for any $\left\{x_{n}\right\}$ in $C$ whenever $\left\{t_{n}\right\}$ converges to 0 . Thus, using Theorem 3.1 we obtain

$$
\bigcap_{k=1}^{\infty} F\left(T_{k}\right) \subset \mathrm{s}-\operatorname{Li}\left(C_{n} \cap D_{n}\right) \subset \mathrm{w}-\operatorname{Ls}\left(C_{n} \cap D_{n}\right) \subset \mathrm{M}-\lim _{n} C_{n}=\bigcap_{k=1}^{\infty} F\left(T_{k}\right),
$$

and therefore $\mathrm{M}-\lim _{n}\left(C_{n} \cap D_{n}\right)=\bigcap_{k=1}^{\infty} F\left(T_{k}\right)$. Consequently, by using Theorems 2.3 and 2.4 , we obtain the following results generalizing the theorems of $\mathrm{Xu}$, and Matsushita and Takahashi, respectively.

Theorem 6.1. Let $C$ be a nonempty bounded closed convex subset of a uniformly convex and smooth Banach space $E$ and $\left\{T_{n}\right\}$ a sequence of nonexpansive mappings of $C$ into itself such that $F=\bigcap_{n=1}^{\infty} F\left(T_{n}\right) \neq \emptyset$ and suppose that it satisfies condition (I). Let $\left\{x_{n}\right\}$ be a sequence generated by

$$
\begin{gathered}
x_{1}=x \in C, \\
C_{n}=\text { clco }\left\{z \in C:\left\|z-T_{n} z\right\| \leq t_{n}\left\|x_{n}-T_{n} x_{n}\right\|\right\}, \\
D_{n}=\left\{z \in C:\left\langle x_{n}-z, J x-J x_{n}\right\rangle \geq 0\right\}, \\
x_{n+1}=\prod_{C_{n} \cap D_{n}} x
\end{gathered}
$$

for each $n \in \mathbb{N}$, where $\left\{t_{n}\right\}$ is a sequence in $(0,1)$ with $t_{n} \rightarrow 0$ as $n \rightarrow \infty$. Then, $\left\{x_{n}\right\}$ converges strongly to $\Pi_{F} x$.

Theorem 6.2. Let $C$ be a nonempty bounded closed convex subset of a uniformly convex and smooth Banach space $E$ and $\left\{T_{n}\right\}$ a sequence of nonexpansive mappings of $C$ into itself such that $F=\bigcap_{n=1}^{\infty} F\left(T_{n}\right) \neq \emptyset$ and suppose that it satisfies condition (I). Let $\left\{x_{n}\right\}$ be a sequence generated by

$$
\begin{gathered}
x_{1}=x \in C, \\
C_{n}=\operatorname{clco}\left\{z \in C:\left\|z-T_{n} z\right\| \leq t_{n}\left\|x_{n}-T_{n} x_{n}\right\|\right\}, \\
D_{n}=\left\{z \in C:\left\langle x_{n}-z, J\left(x-x_{n}\right)\right\rangle \geq 0\right\}, \\
x_{n+1}=P_{C_{n} \cap D_{n}} x
\end{gathered}
$$


for each $n \in \mathbb{N}$, where $\left\{t_{n}\right\}$ is a sequence in $(0,1)$ with $t_{n} \rightarrow 0$ as $n \rightarrow \infty$. Then, $\left\{x_{n}\right\}$ converges strongly to $P_{F} x$.

\section{Acknowledgment}

The first author is supported by Grant-in-Aid for Scientific Research no. 19740065 from Japan Society for the Promotion of Science. This work is Dedicated to Professor Wataru Takahashi on his retirement.

\section{References}

[1] F. E. Browder, "Convergence of approximants to fixed points of nonexpansive non-linear mappings in Banach spaces," Archive for Rational Mechanics and Analysis, vol. 24, pp. 82-90, 1967.

[2] S. Reich, "Strong convergence theorems for resolvents of accretive operators in Banach spaces," Journal of Mathematical Analysis and Applications, vol. 75, no. 1, pp. 287-292, 1980.

[3] W. Takahashi and Y. Ueda, "On Reich's strong convergence theorems for resolvents of accretive operators," Journal of Mathematical Analysis and Applications, vol. 104, no. 2, pp. 546-553, 1984.

[4] B. Halpern, "Fixed points of nonexpanding maps," Bulletin of the American Mathematical Society, vol. 73, pp. 957-961, 1967.

[5] R. Wittmann, "Approximation of fixed points of nonexpansive mappings," Archiv der Mathematik, vol. 58 , no. 5, pp. 486-491, 1992.

[6] N. Shioji and W. Takahashi, "Strong convergence of approximated sequences for nonexpansive mappings in Banach spaces," Proceedings of the American Mathematical Society, vol. 125, no. 12, pp. 3641-3645, 1997.

[7] K. Nakajo and W. Takahashi, "Strong convergence theorems for nonexpansive mappings and nonexpansive semigroups," Journal of Mathematical Analysis and Applications, vol. 279, no. 2, pp. 372 379, 2003.

[8] W. Takahashi, Y. Takeuchi, and R. Kubota, "Strong convergence theorems by hybrid methods for families of nonexpansive mappings in Hilbert spaces," Journal of Mathematical Analysis and Applications, vol. 341, no. 1, pp. 276-286, 2008.

[9] H.-K. Xu, "Strong convergence of approximating fixed point sequences for nonexpansive mappings," Bulletin of the Australian Mathematical Society, vol. 74, no. 1, pp. 143-151, 2006.

[10] S.-Y. Matsushita and W. Takahashi, "Approximating fixed points of nonexpansive mappings in a Banach space by metric projections," Applied Mathematics and Computation, vol. 196, no. 1, pp. 422 $425,2008$.

[11] H. K. Xu, "Inequalities in Banach spaces with applications," Nonlinear Analysis: Theory, Methods $\mathcal{E}$ Applications, vol. 16, no. 12, pp. 1127-1138, 1991.

[12] R. E. Bruck Jr., "On the convex approximation property and the asymptotic behavior of nonlinear contractions in Banach spaces," Israel Journal of Mathematics, vol. 38, no. 4, pp. 304-314, 1981.

[13] G. Beer, Topologies on Closed and Closed Convex Sets, vol. 268 of Mathematics and Its Applications, Kluwer Academic Publishers, Dordrecht, The Netherlands, 1993.

[14] K. Goebel and S. Reich, Uniform Convexity, Hyperbolic Geometry, and Nonexpansive Mappings, vol. 83 of Monographs and Textbooks in Pure and Applied Mathematics, Marcel Dekker, New York, NY, USA, 1984.

[15] W. Takahashi, Nonlinear Functional Analysis, Fixed Point Theory and Its Applications, Yokohama Publishers, Yokohama, Japan, 2000.

[16] W. Takahashi, Convex Analysis and Approximation of Fixed Points, vol. 2 of Mathematical Analysis Series, Yokohama Publishers, Yokohama, Japan, 2000.

[17] Y. I. Alber, "Metric and generalized projection operators in Banach spaces: properties and applications," in Theory and Applications of Nonlinear Operators of Accretive and Monotone Type, vol. 178, pp. 15-50, Marcel Dekker, New York, NY, USA, 1996.

[18] S. Reich, "Constructive techniques for accretive and monotone operators," in Applied Nonlinear Analysis (Proc. Third Internat. Conf., Univ. Texas, Arlington, Tex., 1978), pp. 335-345, Academic Press, New York, NY, USA, 1979.

[19] M. Tsukada, "Convergence of best approximations in a smooth Banach space," Journal of Approximation Theory, vol. 40, no. 4, pp. 301-309, 1984. 
[20] T. Ibaraki, Y. Kimura, and W. Takahashi, "Convergence theorems for generalized projections and maximal monotone operators in Banach spaces," Abstract and Applied Analysis, vol. 2003, no. 10, pp. 621-629, 2003.

[21] Y. Kimura, "On Mosco convergence for a sequence of closed convex subsets of Banach spaces," in Proceedings of the International Symposium on Banach and Function Spaces, M. Kato and L. Maligranda, Eds., pp. 291-300, Kitakyushu, Japan, 2004.

[22] E. Resmerita, "On total convexity, Bregman projections and stability in Banach spaces," Journal of Convex Analysis, vol. 11, no. 1, pp. 1-16, 2004.

[23] H. H. Bauschke and P. L. Combettes, "A weak-to-strong convergence principle for Fejér-monotone methods in Hilbert spaces," Mathematics of Operations Research, vol. 26, no. 2, pp. 248-264, 2001.

[24] K. Nakajo, K. Shimoji, and W. Takahashi, "Strong convergence theorems by the hybrid method for families of nonexpansive mappings in Hilbert spaces," Taiwanese Journal of Mathematics, vol. 10, no. 2, pp. 339-360, 2006.

[25] K. Nakajo, K. Shimoji, and W. Takahashi, "Strong convergence to common fixed points of families of nonexpansive mappings in Banach spaces," Journal of Nonlinear and Convex Analysis, vol. 8, no. 1, pp. 11-34, 2007.

[26] R. E. Bruck Jr., "Properties of fixed-point sets of nonexpansive mappings in Banach spaces," Transactions of the American Mathematical Society, vol. 179, pp. 251-262, 1973.

[27] W. A. Kirk, "A fixed point theorem for mappings which do not increase distances," The American Mathematical Monthly, vol. 72, pp. 1004-1006, 1965.

[28] W. Takahashi, "Weak and strong convergence theorems for families of nonexpansive mappings and their applications," Annales Universitatis Mariae Curie-Skłodowska. Sectio A, vol. 51, no. 2, pp. 277-292, 1997.

[29] W. Takahashi and K. Shimoji, "Convergence theorems for nonexpansive mappings and feasibility problems," Mathematical and Computer Modelling, vol. 32, no. 11-13, pp. 1463-1471, 2000.

[30] Y. Kimura and W. Takahashi, "Weak convergence to common fixed points of countable nonexpansive mappings and its applications," Journal of the Korean Mathematical Society, vol. 38, no. 6, pp. 1275-1284, 2001.

[31] K. Aoyama, Y. Kimura, W. Takahashi, and M. Toyoda, "Approximation of common fixed points of a countable family of nonexpansive mappings in a Banach space," Nonlinear Analysis: Theory, Methods E Applications, vol. 67, no. 8, pp. 2350-2360, 2007.

[32] S. Atsushiba, N. Shioji, and W. Takahashi, "Approximating common fixed points by the Mann iteration procedure in Banach spaces," Journal of Nonlinear and Convex Analysis, vol. 1, no. 3, pp. 351$361,2000$.

[33] N. Shioji and W. Takahashi, "Strong convergence theorems for asymptotically nonexpansive semigroups in Banach spaces," Journal of Nonlinear and Convex Analysis, vol. 1, no. 1, pp. 73-87, 2000.

[34] R. E. Bruck Jr., "A common fixed point theorem for a commuting family of nonexpansive mappings," Pacific Journal of Mathematics, vol. 53, pp. 59-71, 1974.

[35] K. Nakajo, K. Shimoji, and W. Takahashi, "Strong convergence theorems of Browder's type for families of nonexpansive mappings in Hilbert spaces," International Journal of Computational and Numerical Analysis and Applications, vol. 6, no. 2, pp. 173-192, 2004.

[36] T. Suzuki, "On strong convergence to common fixed points of nonexpansive semigroups in Hilbert spaces," Proceedings of the American Mathematical Society, vol. 131, no. 7, pp. 2133-2136, 2003. 